\title{
Strong negative association between intake of Tofu and anemia among Chinese adults in Jiangsu China
}

Zumin Shi, MD, $\mathrm{PhD}^{12}$, Xiaoshu Hu, MD ${ }^{1}$, Baojun Yuan, $\mathrm{MD}^{1}$, Xiaoqun Pan, $\mathrm{MD}^{1}$, Yue Dai, $\mathrm{MD}^{1}$, Gerd Holmboe-Ottesen, $\mathrm{PhD}^{3}$, Julie E Byles, $\mathrm{MD}, \mathrm{PhD}^{2}$

${ }^{1}$ Jiangsu Provincial Center for Disease Control and Prevention, Nanjing, China.

${ }^{2}$ Research Center for Gender, Health and Ageing, Hunter Medical Research Institute, The University of Newcastle, Australia.

${ }^{3}$ Section of Preventive Medicine and Epidemiology, Institute of General Practice and Community Medicine, University of Oslo, P.O Box 1130, N- 0318 Oslo, Norway. (16)

Z. Shi is an associate professor of Jiangsu Provincial Center for Disease Control and Prevention, China, and research fellow of Research Center for Gender, Health, and Ageing, The University of Newcastle, Newcastle, Australia.

$\mathrm{X} . \mathrm{Hu}$ is a professor of Jiangsu Provincial Center for Disease Control and Prevention, Nanjing, China.

B. Yuan is a professor of Jiangsu Provincial Center for Disease Control and Prevention, Nanjing, China.

X. Pan is an associate professor of Jiangsu Provincial Center for Disease Control and Prevention, Nanjing, China.

Y. Dai is an associate professor of Jiangsu Provincial Center for Disease Control and Prevention, Nanjing, China.

G. Holmboe-Ottesen is a professor at the Institute of General Practice and Community Medicine of University of Oslo, Oslo, Norway

J.E. Byles is a professor at the Research Center for Gender, Health and Ageing, Hunter Medical Research Institute, The University of Newcastle, Newcastle, Australia. 
34 Address of corresponding author:

35 Zumin Shi, MD, PhD

36 Department of Nutrition and Food Hygiene,

37 Jiangsu Provincial Center for Disease Control and Prevention.

38172 Jiangsu Road, Nanjing 210009, P. R. China.

39 Telephone number:+86-25-83759341

40 Fax number: $+86-25-83759341$

$41 \quad$ E-mail: zumins@vip.sina.com

42

43 Running head: Tofu intake and anemia of Chinese adults.

44 Word count: Text 2741 Abstract 250 


\section{Abstract}

Background: Anemia is prevalent in China. Tofu made from soybean is a popular food. Soybean is shown to have an effect on iron status. No study has examined the relation between tofu and iron status.

Objective: To investigate the association between tofu intake and anemia among Chinese adults.

Design: A cross-sectional household survey of 2849 men and women aged 20 years and over (mean 47.0, standard deviation [SD] 14.5), from a nationally representative random sample in Jiangsu province undertaken in 2002 (response rate 89.0\%). Tofu intake was assessed by food frequency questionnaire. Nutrient intake was measured by three day weighed food records. Serum ferritin (SF), and hemoglobin $(\mathrm{Hb})$ were measured.

Results: The prevalence of anemia was $18.3 \%$ in men and $31.5 \%$ in women. Mean $\mathrm{Hb}$ increased by quartiles of tofu intake (men: 14.1, 14.0, 14.5 and 14.8; women: 12.4, $12.5,12.6$ and $13.3 \mathrm{~g} / \mathrm{dl}$ ), while the prevalence of anemia decreased concomitantly. Comparing first and fourth quartiles of tofu intake, the prevalence of anemia was $23.9 \%$ vs $10.7 \%$ in men, and $38.1 \%$ vs $16.8 \%$ in women. Tofu intake was inversely associated with SF levels in women. In multivariate analyses, the odds ratio (OR) of anemia for men in fourth compared to first quartile of tofu intake was $0.30(95 \%$ confidence interval [CI] 0.17-0.50), and the corresponding OR for women was 0.31 (95\%CI 0.20-0.47). The association between tofu intake and anemia was independent of iron intake. 
68 Conclusion: Tofu intake was associated with lower risk of anemia among Chinese 69 adults in both genders.

70 Key words: Hemoglobin, anemia, serum ferritin, tofu intake, China 


\section{Introduction}

Iron deficiency affects about 2 billion people worldwide, being one of the leading risk factors for disability and death (1). In developing countries, $42.3 \%$ women and $30.0 \%$ men aged 15-59 years are anemic, with half having iron deficiency anemia (IDA) (2). Even in developed countries, $10.3 \%$ of women are anemic (2). Iron deficiency in developing countries is about twice as frequent as IDA (2). Although anemia can be caused by different factors, the main cause is iron deficiency. Low iron content in the diet and low bioavailability from plant-based diets are main causes of IDA. Other causes of IDA include pregnancy, gastrointestinal blood loss, menstruation, growth and development, intestinal parasites such as hookworm, and Helicobacter pylori infection (1). Iron fortified wheat flour and soy sauce are used in population approaches to prevent IDA (1-3).

Intake of soybeans may prevent anemia through two different mechanisms. First, soybean has a high iron and ferritin content $(4,5)$. Iron from soybean ferritin is highly absorbed and may provide a model for novel, utilizable, plant-based forms of iron for populations with a low iron status (6). Shoyu polysaccharides from soy sauce enhance iron absorption in animals and humans (7). Second, soy intake can lower inflammation levels and thereby reduce metabolic causes of anemia $(1,8-10)$.

At present, few population studies report the association between intake of tofu and anemia. Most other studies on the association between soy and anemia focus on either soy protein or phytoestrogens. Tofu differs from soy protein in that it has a very high calcium content (due to the calcium coagulant used in the curding process). Present knowledge on the association between calcium and iron absorption is controversial (11-14). In this study, it is hypothesized that there would be an association between intake of tofu and anemia and that such an association would be independent of iron intake. This hypothesis was tested among adults in a cross-sectional population survey. 


\section{Subjects and methods}

\section{Population and Sample}

China has a long history of consuming tofu, but there is a large variation in the intake of tofu and other soy products in the population $(15,16)$. There is also a high prevalence of anemia in the Chinese population (around 25\%) (17). Thus, China provides a good population to study the association of tofu intake with anemia.

In 2002, China launched a national study in nutrition and health under the approval of the Chinese Ministry of Health. A multistage cluster sampling method was used to select the participants. The data presented in this article are based on a subsample from Jiangsu (population 73.6 million), one of the provinces in China experiencing rapid economic growth. The rural sample was selected from 6 counties (Jiangyin, Taicang, Suining, Jurong, Sihong and Haimen). From each of the six counties, three towns were randomly selected. The urban sample was selected from two prefecture capital cities (Nanjing and Xuzhou). From each prefecture city, three streets were randomly selected. The six counties and two prefectures cities represented a geographically and economically diverse population with gross domestic product (GDP) ranging from 3221Yuan/capita/year (403 USD) to 35169 Yuan/capita/year (4396 USD) (mean 1993 USD) (18). Nanjing, Jurong, Taichang and Jiangyin are in the South. The south has higher GDP than the north (24702 vs 7183 Yuan). In each town/street, two villages/neighborhoods were further randomly selected. In each village/neighborhood, 30 households were randomly selected. All members in the households including children were invited to take part in the study. The study was 
approved by the ethical committee in Chinese National Center for Disease Control (CDC) and Prevention. Written consents were obtained from all the participants. In this study, only data for adults aged 20 years and over were analyzed.

\section{Measurement and interview}

Participants were interviewed in their homes by trained health workers using a pre-coded questionnaire. Interviews took approximately two hours to complete and included questions on diet, socio-demographic information, medical history, drug treatment, health habits such as cigarette smoking and physical activity, and other lifestyle factors. Height was measured without shoes and weight with light clothing. Body mass index (BMI) was calculated as weight in kilograms divided by the square of the height in metres.

Hemoglobin (Hb) and serum ferritin (SF)

All participants were invited to provide a fasting blood sample. All the blood samples were analyzed for plasma glucose and $\mathrm{Hb}$ in the local centers for disease control and prevention with quality control set by the National CDC and Prevention. Cyanmethemoglobin method was used to measure $\mathrm{Hb}$ (19). A commercially available radioimmunoassay kit (Radioimmunoassay kit for SF, Beijing North Institute of Biological Technology, Beijing) was used to analyze SF by the National CDC in Beijing.

Anemia was defined as a $\mathrm{Hb}$ level below $13 \mathrm{~g} / \mathrm{dl}$ for men and $12 \mathrm{~g} / \mathrm{dl}$ for women (2). The definition of IDA was based on the presence of both anemia and a SF level 
$<15 \mu \mathrm{g} / 1(1)$.

Dietary measurements. Diet in the past year was investigated by a series of detailed questions regarding usual frequency and quantity of intake of 33 foods and beverages. Portion size for each food was established by reference to food models. Subjects were asked to recall the frequency of consumption of individual food items (number of times/day, /week, /month, /year) and the estimated portion size, using local weight units (i.e., a liang which is equivalent to $50 \mathrm{~g}$ ) or cups. Intakes of foods were converted into grams per week and were used in further analysis. The questionnaire includes both wet tofu and dried tofu. Tofu intake was calculated by summing up the intakes of both types. Fresh and dried soybeans were not included in the analysis.

The food frequency questionnaire has been validated $(20,21)$ and reported to be a useful method for the collection of individual food consumption information in a face-to-face interview, but not in self-administered surveys due to the current educational level of the majority of the Chinese population.

Nutrient intake was also measured by three day weighed food records. Food consumption data were analysed using the Chinese Food Composition Table (4).

Socio-economic status (SES) SES was assessed by the question 'What was your family's income per person in 2001?'. The response categories for the question were less than 800, 800-1999, 2000-4999, 5000-9999, 10000-19999 and >20000Yuan. SES was constructed from income: 'low': less than 1999Yuan; 'medium': 2000-4999Yuan; 'high': more than 5000Yuan.

\section{Statistical analyses}

Tofu intake was divided into gender specific quartiles, implying increased intake from quartile 1 to quartile 4. Chi square test was used to compare difference between categorical variables. Logistic regression was used to determine the association between tofu intake and anemia adjusted for socio-demographic factors including residence, age, socioeconomic status (SES), region and education, intake of fruits, vegetables, and animal foods. Estimates were presented in either mean and standard deviation (SD) or odds ratio (OR) and 95\% confidence interval (CI). All the analyses 
172 were performed by using STATA software (version 9, 2005, Stata Corp, College 173 Station, TX). 


\section{Results}

The total sample included 1308 men and 1541 women, of them 711 participants were from the urban area. The response rate of the study was $89.0 \%$. The mean age of the sample was 47.0 years (SD 14.5). Table 1 shows the demographic characteristics of the study population by gender. The prevalence of anemia was $18.3 \%$ in men and $31.5 \%$ in women. The distribution of SF was not normal, and skewed to the lower values. Only $2.1 \%$ men and $15.1 \%$ women had SF $<15 \mu \mathrm{g} / 1$. The prevalence of IDA was thus low, 6.3\% among women and $0.7 \%$ among men. Tofu intake was not normally distributed and was skewed to the lower values. The mean tofu intake was $50.9 \mathrm{~g} /$ day for men and $44.5 \mathrm{~g} /$ day for women.

Table 2 shows the sample characteristics across tofu intake quartiles. The mean daily intake of tofu in the lowest and highest quartile ranged from 9.1 to $119.8 \mathrm{~g}$ in men and 7.0 to $110.4 \mathrm{~g}$ in women. Daily intake of calcium, iron, magnesium, and fruits was positively associated with increasing tofu intake in both genders, while in regard to intake of meat this association was only significant for women. The intake of vitamin $\mathrm{C}$ varied according to quartiles of tofu intake only in women, but there was no consistent trend. No significant association between tofu intake and vegetable intake was found. Participants with low SES tended to have higher tofu intake than those with higher SES.

Figure 1 shows the association between tofu intake and $\mathrm{Hb}$. Tofu intake was positively associated with $\mathrm{Hb}$ in men and women (Table 3). The probability of having a $\mathrm{Hb}$ level in the highest quartile increased across the quartiles of tofu intake in men and women. A clear decreasing trend of prevalence of anemia was seen across quartiles of tofu intake from low to high in men and women. The prevalence of anemia in the first and fourth quartiles of tofu intake was $23.9 \%$ vs $10.7 \%$ in men; the corresponding figure was $38.1 \%$ vs $16.8 \%$ in women $(\mathrm{p}<0.0001)$. There was no statistically significant difference in mean SF across quartiles of tofu intake. However, the probability of being in the highest quartile of SF decreased across tofu intake quartiles in women ( $p$ 
204 for trend is 0.030 ). Women in the lowest tofu intake group had the highest probability 205 of being in the highest SF quartile (Q1 vs Q4: 31.0\% vs 20.3\%). No such association 206 was found in men.

208 In multivariate analysis, after adjusting for age, BMI, residence, SES, education, 209 intake of fruits, vegetables, and animal foods, people in the highest quartile of tofu 210 intake had a lower risk of anemia compared with the lowest quartile (Q1) (men: OR $2110.30 \quad(95 \%$ CI $0.17-0.50)$; women 0.31 (95\%CI 0.20-0.47) (Table 4). Further 212 adjustment of iron intake did not change the estimates. Adding calcium intake 213 quartiles into the multivariate model did not change the association. Calcium intake 214 was not associated with anemia in the sample while iron intake was inversely 215 associated with anemia in women (data not shown). 


\section{Discussion}

217 In this cross-sectional study, high intake of tofu was associated with lower risk of

218 anemia in both men and women. The association was still remained highly significant

219 after adjusting for sociodemographic characteristics, BMI, intake of foods known to

220 affect iron status, and iron. Tofu intake was negatively associated with having higher

221 SF in women but not in men.

222 The total iron intake in the sample was found to be higher than in Western populations,

223 but similar with findings from another study in China (22). The iron intake increased

224 somewhat across the quartiles of tofu intake. This probably due to the fact that tofu

225 has a high content of iron, much higher than in rice and wheat flour (4). However,

226 tofu is consumed in much lower quantities thus contributing a relatively low

227 proportion of total iron intake except in the highest quartiles (110-120 $\mathrm{g}$ tofu

228 consumed in the fourth quartile means less than $2 \mathrm{mg}$ iron per day). Although soybean

229 contains phytate, which can decrease the bioavailbility of iron, this compound is

230 degraded in the production of tofu, which implies soaking, grinding, and boiling (23).

231 The present results are consistent with present evidence of high bioavailability of iron

232 from soybean or soybean in population studies $(5,6,24)$, despite the fact that tofu in

233 China has a high molar ratio of phytate to iron, ranging from 16 - 61 (23).

234 Intake of meat and fruits increased across the quartiles of tofu intake from low to high.

235 Meat intake is a known enhancing factor of non-heme iron absorption (24). Also,

236 fruits and vegetables may enhance absorption of non-heme iron in the diet due to the

237 high content of vitamin C (25). The intake of this vitamin did not vary by tofu intake

238 quartiles in men, and even though there was a change in women, this trend was not

239 consistent and could not explain the variation in anemia.

240 Although the mechanism is not clear, tofu intake is negatively associated with blood

241 lead levels in the Chinese population (26). Whether decreased blood lead level is one

242 of the pathways in the association between tofu intake and anemia needs further

243 research.

244 The association between calcium intake and anemia is ambiguous (11-14). In this

245 study, no effect of calcium intake on the association between tofu intake and anemia 
was found. This finding may be due to the fact that the intake of calcium was low in all groups even if there were differences according to different tofu intake groups. The association between tofu intake and anemia was independent of iron intake. After adjusting for intake of fruits and vegetables and animal foods, the association between intake of Tofu and anemia still remained.

Another potential cause of anemia could be high levels of inflammation and infection in the subjects, as shown in a recent review (1). Soy intake was found to be negatively associated with inflammation. In a study of postmenopausal women with metabolic syndrome, short-term soy nut consumption was related to a reduction of some markers of inflammation (8). Soy contains fiber, polyunsaturated fat, and phytoestrogens, which are all negatively associated with levels of inflammatory markers (8).

In the present study, intake of tofu was also positively associated with magnesium intake. Magnesium has been found to be inversely associated with markers of systematic inflammation (27-29). Magnesium supplementation increases erythrocytes and hemoglobin levels of athletes (30).

It is common to use SF as a marker of stored body iron (31), but SF is also increased by inflammation and infection $(32,33)$. The negative association between intake of tofu and high SF in women suggests an anti-inflammatory effect of tofu. The highest prevalence of anemia combined with high SF was observed in the low tofu intake group. Furthermore, due to the very small percentage having low SF the prevalence of IDA was low, despite the high prevalence of anemia. Since Thalassaemia is not a problem in this area with a prevalence of $0.09 \%(34)$, it is reasonable to assume that a considerable proportion of the anemia in the population is caused by inflammation. In the study, markers of inflammation such as c-reactive protein, were not measured, but it has been reported that the prevalence of the hepatitis B virus marker is $42.6 \%$ and chronic hepatitis B surface antigen carriage is $10.2 \%$ in various parts of China (35). In the Shanghai Women's Health Study, the intake of soy foods included 11 items. In this study, the food frequency questionnaire included 4 food items related to soy intake. For simplicity in the analysis, the wet and dry tofu were summed up by giving the same weight to each item. This may underestimate the association between intake 
of tofu and iron status as the wet tofu contains a lot of water. Different mechanisms may be involved, and the effect of soy ferritin, isoflavonoids, and soy protein on the risk of anemia was not assessed.

There are several limitations to this study. The cross-sectional study design and the lack of measurement of some potential confounding factors including inflammation markers imply that no conclusions on the etiological association between tofu consumption and $\mathrm{Hb}$ concentration can be drawn. It was also not possible to control for the potential confounding effects of these infections in the analysis. Furthermore, the potentially complex interactions of multiple nutrients with iron cannot be assessed, and therefore cannot encourage tofu intake for the purpose of anemia prevention without further investigation.

\section{Conclusions}

This is the first study to report the association between tofu intake and anemia at the population level. It supports the idea of adding soy in the healthy eating index as suggested by the US Department of Agriculture. The findings indicate that the anemia in the region could be related to high rates of infection and inflammatory processes. Although the region is one of the richest in China, the prevalence of anemia is the highest in China as observed by three national nutrition surveys (36). The study may have public health significance. Except for the iron fortified soysauce intervention project in this region, there is no other intervention project yet. Taking into account the long tradition of consuming tofu in the country, its low economic burden, as well as the health benefits, it may be promising to promote tofu as part of a healthy food choice in the prevention of anemia. The results may provide useful knowledge to other countries with the tradition of eating tofu that have a high prevalence of anemia.

In conclusion, a high intake of tofu was associated with a lower prevalence of anemia. 


\section{Reference}

1. Zimmermann MB, Hurrell RF. Nutritional iron deficiency. Lancet. 2007;370:511-20.

2. WHO. Iron Deficiency Anaemia. Assessment, Prevention and Control: A

3. Mannar V, Gallego EB. Iron fortification: country level experiences and

11. Cook JD, Dassenko SA, Whittaker P. Calcium supplementation: effect on iron 
absorption. Am J Clin Nutr. 1991;53:106-11.

12. Grinder-Pedersen L, Bukhave K, Jensen M, Hojgaard L, Hansen M. Calcium from milk or calcium-fortified foods does not inhibit nonheme-iron absorption from a whole diet consumed over a 4-d period. Am $J$ Clin Nutr. 2004;80:404-9.

13. Reddy MB, Cook JD. Effect of calcium intake on nonheme-iron absorption from a complete diet. Am J Clin Nutr. 1997;65:1820-5.

14. Roughead ZK, Zito CA, Hunt JR. Inhibitory effects of dietary calcium on the initial uptake and subsequent retention of heme and nonheme iron in humans: comparisons using an intestinal lavage method. Am $J$ Clin Nutr. 2005;82:589-97.

15. Liu Z, Li W, Sun J, Liu C, Zeng Q, Huang J, Yu B, Huo J. Intake of soy foods and soy isoflavones by rural adult women in China. Asia Pac J Clin Nutr. 2004;13:204-9.

16. Yang G, Shu XO, Jin F, Zhang X, Li HL, Li Q, Gao YT, Zheng W. Longitudinal study of soy food intake and blood pressure among middle-aged and elderly Chinese women. Am J Clin Nutr. 2005;81:1012-7.

17. Li L, Rao K, Kong L, Yao C, Xiang H, Zhai F, Ma G, Yang X. A description on the Chinese national nutrition and health survey in 2002. Zhonghua liu Xing Bing Xue Za Zhi. 2005;26:474-84.

18. Jiangsu Bureau of statistics. Statistical yearbook of Jiangsu. Beijing: China Statistics Press, 2002.

19. Dallman PR. Diagnosis of anemia and iron deficiency: analytic and biological variations of laboratory tests. Am J Clin Nutr. 1984;39:937-41.

20. Zhang G, Zhu ZM, Zhao ZG, Ni GX, Yan ZC, Li Q, Liu HY. Comparative study of different diagnostic criteria of metabolic syndrome. Zhonghua Yi Xue Za Zhi. 2005;85:490-1.

21. Li YP, He YN, Zhai FY, Yang XG, Hu XQ, Zhao WH, Ma GS. Comparison of assessment of food intakes by using 3 dietary survey methods. Zhonghua $Y u$ Fang Yi Xue Za Zhi. 2006;40:273-80. 
22. Chen Z, Shu XO, Yang G, Li H, Li Q, Gao YT, Zheng W. Nutrient intake among Chinese women living in Shanghai, China. Br J Nutr. 2006;96:393-9.

23. Ma G, Jin Y, Piao J, Kok F, Guusje B, Jacobsen E. Phytate, calcium, iron, and zinc contents and their molar ratios in foods commonly consumed in China. $J$ Agric Food Chem. 2005;53:10285-90.

24. Hallberg L, Rossander L. Improvement of iron nutrition in developing countries: comparison of adding meat, soy protein, ascorbic acid, citric acid, and ferrous sulphate on iron absorption from a simple Latin American-type of meal. Am J Clin Nutr. 1984;39:577-83.

25. Lopez MA, Martos FC. Iron availability: An updated review. Int J Food Sci Nutr. 2004;55:597-606.

26. Chen C, Wang X, Chen D, Li G, Ronnenberg A, Watanabe H, Wang X, Ryan L, Christiani DC, Xu X. Tofu consumption and blood lead levels in young Chinese adults. Am J Epidemiol. 2001;153:1206-12.

27. Song Y, Li TY, van Dam RM, Manson JE, Hu FB. Magnesium intake and plasma concentrations of markers of systemic inflammation and endothelial dysfunction in women. Am J Clin Nutr. 2007;85:1068-74.

28. Bo S, Durazzo M, Guidi S, Carello M, Sacerdote C, Silli B, Rosato R, Cassader M, Gentile L, Pagano G. Dietary magnesium and fiber intakes and inflammatory and metabolic indicators in middle-aged subjects from a population-based cohort. Am J Clin Nutr. 2006;84:1062-9.

29. King DE, Mainous AG, 3rd, Geesey ME, Ellis T. Magnesium intake and serum C-reactive protein levels in children. Magnes Res. 2007;20:32-6.

30. Cinar V, Nizamlioglu M, Mogulkoc R, Baltaci AK. Effects of magnesium supplementation on blood parameters of athletes at rest and after exercise. Biol Trace Elem Res. 2007;115:205-12.

31. Cook JD, Lipschitz DA, Miles LE, Finch CA. Serum ferritin as a measure of iron stores in normal subjects. Am J Clin Nutr. 1974;27:681-7.

32. Pan Y, Jackson RT. Ethnic difference in the relationship between acute inflammation and serum ferritin in US adult males. Epidemiol Infect. 
2007:1-11.

396 33. Baynes RD. Assessment of Iron Status. Clinical Biochemistry. 1996;29:209-215.

398 34. Zeng YT, Huang SZ. Disorders of haemoglobin in China. J Med Genet. $1987 ; 24: 578-83$.

400 35. Yao GB. Importance of perinatal versus horizontal transmission of hepatitis B 401 virus infection in China. Gut. 1996;38 Suppl 2:S39-42.

402 36. Chang $\mathrm{S}$, Ge $\mathrm{K}$, Zhai F, Jia F, Xu X. The analysis of nutritional factors on 403 anemia in Chinese adults. Acta Nutrimenta Sinica. 1998;20:132-137.

404 
Table 1 Characteristic of the sample by genders among adults in Jiangsu China 2002

\begin{tabular}{|c|c|c|}
\hline & $\operatorname{Men}(n=1308)$ & Women $(n=1541)$ \\
\hline Age, yrs (mean, SD ${ }^{\mathrm{a}}$ ) & $47.2(14.6)$ & $46.8(14.4)$ \\
\hline $\mathrm{Hb}^{\mathrm{b}}, \mathrm{g} / \mathrm{dl}$ (mean, SD) & $14.3(1.7)$ & $12.7(1.5)$ \\
\hline Anemia $(\%)^{\mathrm{c}}$ & $18.3(16.3-20.6)$ & $31.5(29.2-33.9)$ \\
\hline $\mathrm{SF}^{\mathrm{d}}, \mu \mathrm{g} / 1$ (mean, SD) & $131.9(90.1)$ & $71.1(71.5)$ \\
\hline$<15 \mu \mathrm{g} / 1(\%)$ & 2.1 & 15.1 \\
\hline$\geq 200 \mu \mathrm{g} / 1(\%)$ & 18.6 & 5.8 \\
\hline $\operatorname{IDA}(\%)^{\mathrm{e}}$ & 0.7 & 6.3 \\
\hline \multicolumn{3}{|c|}{ Nutrients and foods intake (mean, SD) } \\
\hline Iron, mg/day & $28.2(12.0)$ & $23.4(9.5)$ \\
\hline Magnesium, mg/day & $363.9(151.5)$ & $305.8(129.9)$ \\
\hline Calcium, mg/day & $455.0(224.3)$ & $388.8(190.9)$ \\
\hline Vitamin $\mathrm{C}, \mathrm{mg} /$ day & $65.6(38.7)$ & $60.4(38.0)$ \\
\hline Tofu, g/day & $50.9(51.9)$ & $44.5(28.6)$ \\
\hline Fruits, g/day & $61.7(85.9)$ & $66.9(89.0)$ \\
\hline Vegetables, g/day & $260.7(166.0)$ & 247.3(161.9) \\
\hline Meat, g/day & $69.0(65.6)$ & $52.1(54.5)$ \\
\hline $\mathrm{BMI}^{\mathrm{f}}, \mathrm{kg} / \mathrm{m}^{2}$ (mean, SD) & $23.4(3.2)$ & $23.6(3.7)$ \\
\hline Overweight $(\%)^{\mathrm{g}}$ & 29.2 & 30.7 \\
\hline Urban dwellers (\%) & 25.2 & 24.7 \\
\hline South dwellers $(\%)$ & 53.7 & 52.0 \\
\hline \multicolumn{3}{|l|}{ Education $(\%)$} \\
\hline Primary & 36.0 & 57.5 \\
\hline Junior school & 43.5 & 30.1 \\
\hline High school & 16.3 & 10.8 \\
\hline University & 4.2 & 1.6 \\
\hline \multicolumn{2}{|l|}{${ }^{\mathrm{a}}$ SD-Standard deviation. } & ${ }^{\mathrm{b}}$ Hb-hemoglobin \\
\hline \multicolumn{3}{|c|}{$\begin{array}{l}\text { c Anemia was defined as } \mathrm{Hb} \text { level below } 13 \mathrm{~g} / \mathrm{dl} \text { for men and } 12 \mathrm{~g} / \mathrm{dl} \text { for women. } \\
\mathrm{d} \text { SF-Serum ferritin. }\end{array}$} \\
\hline \multicolumn{3}{|l|}{$\begin{array}{l}{ }^{\mathrm{e}} \text { IDA-iron deficiency an } \\
\mathrm{SF}<15 \mu \mathrm{g} / \mathrm{l} \text {. } \\
{ }^{\mathrm{f}} \text { BMI-Body mass index. }\end{array}$} \\
\hline \multicolumn{3}{|l|}{${ }^{\mathrm{g}}$ Defined as $\quad \mathrm{BMI} \geq 25 \mathrm{~kg} / \mathrm{m}^{2}$} \\
\hline
\end{tabular}


Table 2 Sample characteristics across tofu intake quartiles among adults in Jiangsu China $2002(n=2849)$

\begin{tabular}{|c|c|c|c|c|c|c|c|c|c|c|}
\hline \multirow{3}{*}{$\overline{\text { Intake of tofu (g/day) }}$} & \multicolumn{5}{|c|}{ Men } & \multicolumn{5}{|c|}{ Women } \\
\hline & \multicolumn{4}{|c|}{$\mathrm{Q}^{\mathrm{a}}(\mathrm{n}=330) \mathrm{Q} 2(\mathrm{n}=341) \mathrm{Q} 3(\mathrm{n}=320) \mathrm{Q} 4(\mathrm{n}=317)$} & \multirow[t]{2}{*}{$\mathrm{P}^{\mathrm{b}}$} & \multicolumn{4}{|c|}{$\mathrm{Q} 1(\mathrm{n}=394) \mathrm{Q} 2(\mathrm{n}=392) \mathrm{Q} 3(\mathrm{n}=416) \mathrm{Q} 4(\mathrm{n}=339)$} & \multirow[t]{2}{*}{$\mathrm{P}$} \\
\hline & & & & & & & & & & \\
\hline Mean & 9.1 & 28 & 50.1 & 119.8 & $<0.001$ & 7.0 & 24.2 & 45.5 & 110.4 & $<0.001$ \\
\hline $\mathrm{SD}^{\mathrm{c}}$ & 6.1 & 4.9 & 7.6 & 62.2 & & 5.0 & 4.4 & 8.6 & 54.5 & \\
\hline Min & 0 & 20.7 & 36.4 & 65.7 & & 0.0 & 15.0 & 29.3 & 58.6 & \\
\hline Max & 20 & 35.7 & 64.3 & 600 & & 14.3 & 28.6 & 57.1 & 452.9 & \\
\hline \multicolumn{11}{|l|}{$\begin{array}{l}\text { Daily foods and nutrients } \\
\text { intake }^{\mathrm{d}}\left(\text { Mean, } \mathrm{SE}^{\mathrm{e}}\right)\end{array}$} \\
\hline Calcium (mg/day) & $445(11)$ & $441(11)$ & $460(12)$ & $471(12)$ & 0.117 & $387(9)$ & $369(9)$ & $384(9)$ & $419(9)$ & 0.001 \\
\hline Iron (mg/day) & $27(1)$ & $28(1)$ & $28(1)$ & $30(1)$ & 0.001 & $23.2(0.4)$ & $22.6(0.4)$ & $23.2(0.3)$ & $24.9(0.4)$ & $<0.001$ \\
\hline Vitamin C (mg/day) & $67(2)$ & $63(2)$ & $63(2)$ & $65(2)$ & 0.625 & $62(2)$ & $59(2)$ & $57(2)$ & $63(2)$ & 0.041 \\
\hline Magnesium (mg/day) & $352(6)$ & $353(6)$ & $359(6)$ & $392(6)$ & $<0.001$ & $305(5)$ & $286(5)$ & $301(5)$ & $335(5)$ & $<0.001$ \\
\hline Meat (g/day) & $67(4)$ & $63(4)$ & $73(4)$ & $72(4)$ & 0.141 & $45(3)$ & $51(3)$ & $56(3)$ & $57(4)$ & 0.006 \\
\hline Fruits (g/day) & $51(5)$ & $60(5)$ & $63(5)$ & $72(5)$ & 0.012 & $56(4)$ & $61(4)$ & $73(4)$ & $77(4)$ & 0.002 \\
\hline Vegetables (g/day) & 261(9) & 244(9) & $268(9)$ & $272(9)$ & 0.135 & $256(8)$ & 233(8) & $246(8)$ & $255(9)$ & 0.178 \\
\hline \multicolumn{11}{|l|}{ Age (yrs) } \\
\hline Mean & 48.4 & 48.5 & 46.1 & 46.4 & 0.058 & 48.3 & 45.5 & 46.2 & 47 & 0.046 \\
\hline SD & 14.8 & 13.9 & 15 & 14.4 & & 15.3 & 13.3 & 14.4 & 14.3 & \\
\hline \multicolumn{11}{|l|}{ Body mass index $\left(\mathrm{kg} / \mathrm{m}^{2}\right)$} \\
\hline Mean & 23.5 & 23.3 & 23.6 & 23.2 & 0.369 & 23.4 & 23.5 & 23.6 & 24.1 & 0.059 \\
\hline SD & 3.3 & 3.2 & 3.2 & 3.3 & & 3.7 & 3.6 & 3.6 & 3.8 & \\
\hline \multicolumn{11}{|l|}{ Socio-economic status } \\
\hline Low & 28.3 & 26.9 & 27.1 & 47.5 & & 31.6 & 24.6 & 30.3 & 44.8 & \\
\hline
\end{tabular}




\begin{tabular}{lcccccccccc}
\hline Medium & 32.6 & 35.5 & 33.4 & 25.6 & $<0.001$ & 32.9 & 39.7 & 30.8 & 26.8 & $<0.001$ \\
$\quad$ High & 39.1 & 37.6 & 39.4 & 26.9 & & 35.5 & 35.6 & 38.8 & 28.3 & \\
Education (\%) & & & & & & & & & & \\
$\quad$ Primary & 38.5 & 38.4 & 26.9 & 40.1 & & 60.6 & 57.1 & 51.9 & 61.4 & \\
$\quad$ Junior school & 44.9 & 37.5 & 49.7 & 42.3 & 0.006 & 28.5 & 29.9 & 33.9 & 27.7 & 0.200 \\
$\quad$ High school & 13.6 & 19.1 & 18.1 & 14.2 & & 9.2 & 11.0 & 13.2 & 9.4 & \\
$\quad$ University & 3.0 & 5.0 & 5.3 & 3.5 & & 1.8 & 2.0 & 1.0 & 1.5 & \\
Residence (\%) & & & & & & & & & & \\
$\quad$ Urban & 20.0 & 24.9 & 32.2 & 24.0 & 0.004 & 20.3 & 25.3 & 28.6 & 24.5 & 0.056 \\
$\quad$ Rural & 80.0 & 75.1 & 67.8 & 76.0 & & 79.7 & 74.7 & 71.4 & 75.5 & \\
Region (\%) & & & & & & & & & & \\
$\quad$ South & 55.8 & 57.8 & 56.9 & 43.9 & 0.001 & 48.2 & 59.4 & 54.3 & 45.1 & $<0.001$ \\
$\quad$ North & 44.2 & 42.2 & 43.1 & 56.2 & & 51.8 & 40.6 & 45.7 & 54.9 \\
\hline
\end{tabular}

${ }^{\mathrm{a}}$ Q1Stands for the lowest quartile

${ }^{\mathrm{b}} \mathrm{Chi}$-square test for categorical variables and ANOVA for continuous variables

${ }^{c}$ SD-Standard deviation

${ }^{\mathrm{d}}$ Energy adjusted

${ }^{\mathrm{e}} \mathrm{SE}-$ Standard error 
Table 3 Association between quartiles of tofu intake and hemoglobin, serum ferritin and anemia among men and women in Jiangsu China

\begin{tabular}{|c|c|c|c|c|c|c|c|c|c|c|}
\hline \multirow{3}{*}{$\overline{\mathrm{Hb}^{\mathrm{c}}}$} & \multicolumn{5}{|c|}{ Men } & \multicolumn{5}{|c|}{ Women } \\
\hline & \multicolumn{4}{|c|}{$\mathrm{Q} 1^{\mathrm{a}}(\mathrm{n}=330) \mathrm{Q} 2(\mathrm{n}=341) \mathrm{Q} 3(\mathrm{n}=320) \mathrm{Q} 4(\mathrm{n}=317)$} & \multirow[t]{2}{*}{$\mathrm{P}^{\mathrm{b}}$} & \multicolumn{4}{|c|}{$\mathrm{Q} 1(\mathrm{n}=394) \mathrm{Q} 2(\mathrm{n}=392) \mathrm{Q} 3(\mathrm{n}=416) \mathrm{Q} 4(\mathrm{n}=339)$} & \multirow[t]{2}{*}{$p$} \\
\hline & & & & & & & & & & \\
\hline Mean (g/dl) & 14.1 & 14.0 & 14.5 & 14.8 & $<0.001$ & 12.4 & 12.5 & 12.6 & 13.3 & $<0.001$ \\
\hline $\mathrm{SD}^{\mathrm{d}}$ & 1.7 & 1.6 & 1.6 & 1.7 & & 1.6 & 1.5 & 1.5 & 1.4 & \\
\hline \multicolumn{11}{|c|}{$\mathrm{Hb}>$ cut-off, ${ }^{\mathrm{e}}$ fourth } \\
\hline quartile $(\%)$ & 21.1 & 17.0 & 26.3 & 35.6 & $<0.001$ & 21.3 & 21.3 & 23.6 & 33.9 & $<0.001$ \\
\hline Anemia $(\%)^{\mathrm{f}}$ & 23.9 & 23.5 & 14.7 & 10.7 & $<0.001$ & 38.1 & 37.2 & 31.7 & 16.8 & $<0.001$ \\
\hline \multicolumn{11}{|l|}{$\mathrm{SF}^{\mathrm{g}}$} \\
\hline Mean $(\mu \mathrm{g} / \mathrm{l})$ & 135.6 & 129.5 & 134.5 & 128 & 0.569 & 75.1 & 74.0 & 66 & 69.5 & 0.540 \\
\hline SD & 93.1 & 91.3 & 88.4 & 87.4 & & 71.4 & 73.3 & 66.6 & 75.1 & \\
\hline \multicolumn{11}{|c|}{$\mathrm{SF}>$ cut-off $^{\mathrm{h}}$, fourth } \\
\hline quartile $(\%)$ & 25.5 & 24.5 & 25.8 & 24.2 & 0.858 & 31.0 & 25.3 & 23.4 & 20.3 & 0.030 \\
\hline
\end{tabular}

${ }^{\mathrm{a}}$ Q1 stands for the lowest quartile.

${ }^{b}$ Chi-square test for categorical variables and ANOVA for continuous variables, in the test for mean SF difference, the value of SF was log transformed

${ }^{c} \mathrm{Hb}$-Hemoglobin

${ }^{\mathrm{d}} \mathrm{SD}-$ Standard deviation

${ }^{\mathrm{e}} \mathrm{Hb} \geq 15.5 \mathrm{~g} / \mathrm{dl}$ in men and $\mathrm{Hb} \geq 13.7 \mathrm{~g} / \mathrm{dl}$ in women 
${ }^{\mathrm{f}}$ Anemia was defined as $\mathrm{Hb}$ level below $13 \mathrm{~g} / \mathrm{dl}$ for men and $12 \mathrm{~g} / \mathrm{dl}$ for women.

${ }^{\mathrm{g}} \mathrm{SF}-\mathrm{Serum}$ ferritin

${ }^{\mathrm{h}} \mathrm{SF} \geq 175.6 \mu \mathrm{g} / \mathrm{l}$ in men and $\mathrm{SF} \geq 95.6 \mu \mathrm{g} / \mathrm{l}$ in women 
Table 4 Odds ratio (OR $95 \% \mathrm{CI}^{\mathrm{a}}$ ) for anemia according to tofu intake quartiles in Chinese adults $(n=2849)$

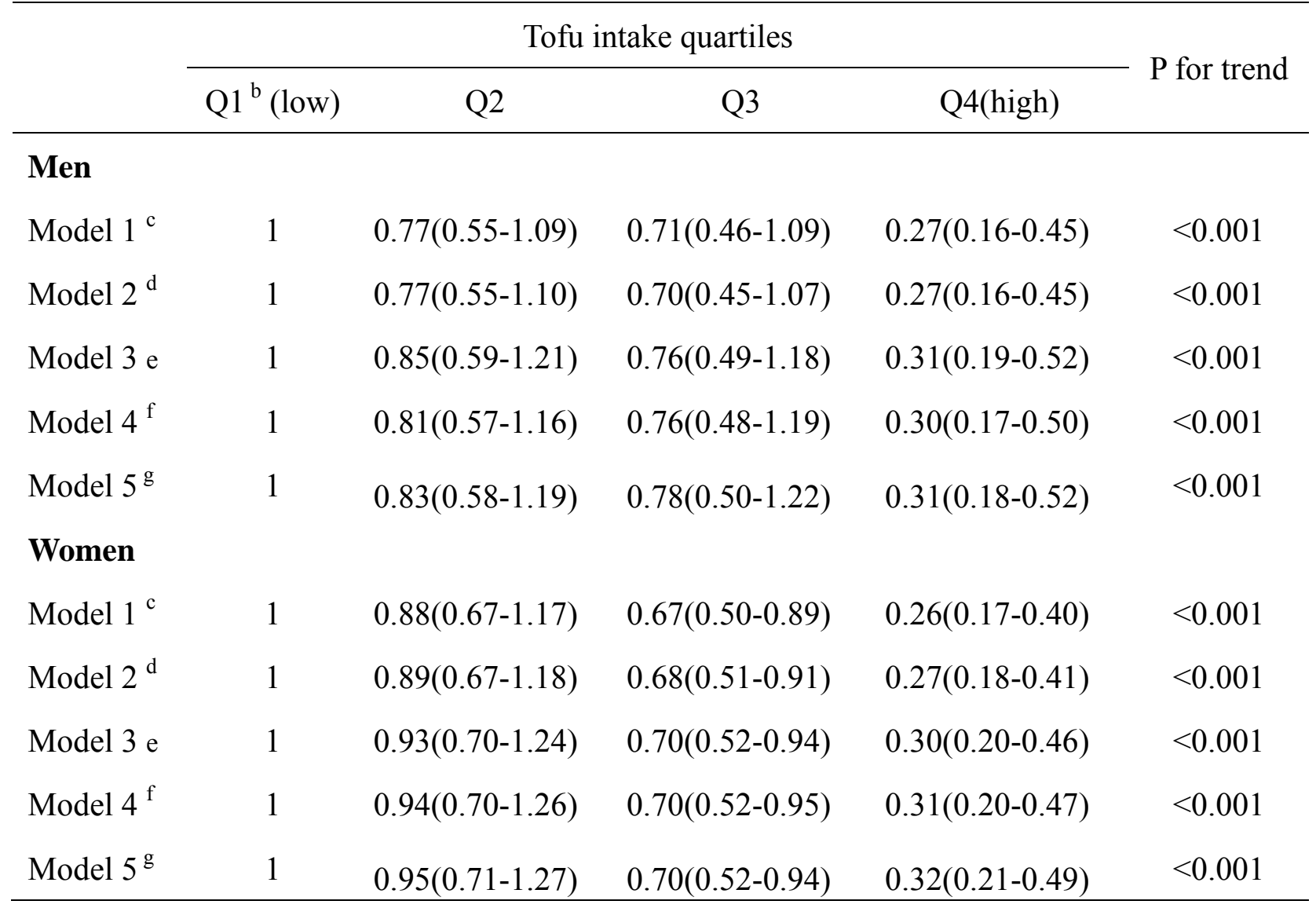

${ }^{\mathrm{a}}$ CI-Confidence interval.

${ }^{\mathrm{b}} \mathrm{Q} 1$ stands for the lowest quartile.

${ }^{\mathrm{c}}$ Adjusted for age

${ }^{\mathrm{d}}$ Adjusted for age, body mass index (continuous)

e Adjusted for age, body mass index, urban/rural, household socio-economic status, education, south/north

${ }^{\mathrm{f}}$ Additional adjusted for intake of fruits and vegetables, intake of pork, beef and lamb (continuous).

${ }^{\mathrm{g}}$ Additional adjusted for intake of energy and iron 


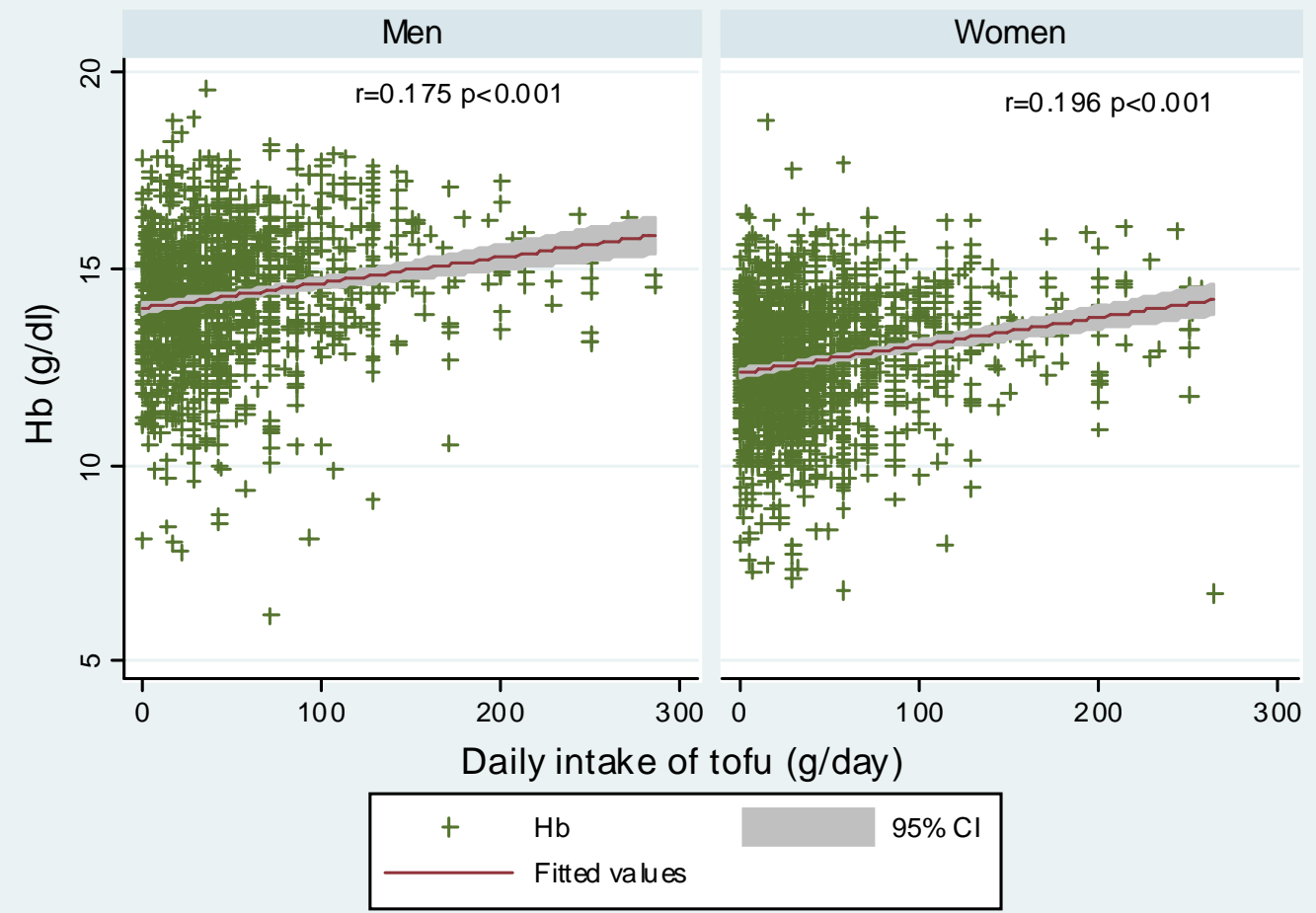

Fig 1 Association between daily intake of tofu and hemoblobin $(\mathrm{Hb})$ (excluded 9 participants with tofu intake $>300 \mathrm{~g} /$ day, $\mathrm{n}=2840$ ) 